\title{
O NEOLIBERALISMO: DESIGUALDADES EDUCACIONAIS E A ALIENAÇÃO
}

Stela Galbardi de Resende, Roseli Gall do Amaral da Silva.

Universidade Estadual de Maringá - UEM, Faculdade de Astorga, Mestrado em Educação, Astorga, PR. E-mail: stela.galbardi@gmail.com.

\section{RESUMO}

Este trabalho tem como objetivo refletir sobre o ideário neoliberal no que diz respeito as suas implicações na educação, de como a economia política se articula objetivando garantir a reprodução da forma de pensar capitalista. Busca-se estabelecer principalmente a interlocução utilizando fontes como: Adam Smith (1983); Marx (1984); Saviani (1991). O neoliberalismo propõe o modelo educacional baseado no trabalho alienado que está ligado à divisão de classes, onde o direcionamento da educação escolar é primeiramente para o mundo do trabalho, enfatizando uma educação unilateral, mais técnica e reprodutiva. Na busca pela formação do homem omnilateral, faz-se necessário discutir a história da economia política, conceituar neoliberalismo e suas formas de articulação na área educacional.

Palavras-chave: Educação, neoliberalismo, desigualdades educacionais.

\section{NEOLIBERALISM: EDUCATIONAL INEQUALITIES AND ALIENATION}

\begin{abstract}
This paper aims to reflect on the neoliberal ideology with regard to its implications in education, on how political economy articulates in order to ensure the reproduction of the capitalist way of thinking. The main aim is to establish dialogue using sources such as: Adam Smith (1983); MARX (1984); SAVIANI (1991). Neoliberalism proposes the educational model based on alienated work that is linked to the division of classes, where the direction of school education is primarily for the world of work, emphasizing a unilateral, more technical and reproductive education. In the search for the formation of the omnilateral man, it is necessary to discuss the history of political economy, to conceptualize neoliberalism and its forms of articulation in the educational area.
\end{abstract}

Keywords: Education, neoliberalism, educational inequalities. 


\section{INTRODUÇÃO}

Para discutir qualidade de ensino, desigualdades educacionais, o neoliberalismo e suas implicações na educação, faz-se necessário primeiramente definir como fenômeno próprio dos seres humanos, a educação, e o trabalho educativo. Em seu livro Pedagogia Histórico-Crítica: primeiras aproximações, Saviani (2008) define que educação é o ato de produzir, direta e intencionalmente, em cada indivíduo singular, a humanidade que é produzida histórica e coletivamente pelo conjunto dos homens.

Assim, o objeto da educação diz respeito, de um lado à identificação dos elementos culturais que precisam ser assimilados pelos indivíduos da espécie humana para que eles se tornem humanos e, por outro lado, e ao mesmo tempo, à descoberta das formas mais adequadas para atingir esse objetivo. Nesse sentido, é uma atividade planejada para atender a uma finalidade que está ligada a um período histórico, culturalmente datado pelas necessidades sociais as quais pretende atender para a produção da existência humana.

\section{METODOLOGIA}

A pesquisa bibliográfica realizada permitiu melhor situar o tema e as reflexões teóricas que problematizam e compreendem o fenômeno das desigualdades educacionais e a alienação não como algo constituído de forma natural e linear na sociedade, mas sim como algo pertencente a uma sociedade determinada por múltiplas relações sociais, econômicas e políticas datadas, ou seja, relações essas construídas pelos homens por meio do trabalho e das lutas de classes, imbricado numa relação dialética complexa.

Segundo Gentil Corazza (1996, p. 38), o conhecimento concreto da realidade só é possível se as partes, abstraídas do todo pelo pensamento, forem rearticuladas ao todo concreto. Nesse sentido, foram analisadas as obras de Adam Smith e Karl Marx referentes a economia e seus reflexos no processo educativo.

\section{RESULTADOS}

Partindo do princípio que o sistema político-econômico atual tem seus fundamentos no neoliberalismo, faz-se importante entendê-lo desde a sua essência. Admitindo o conceito de que a economia é uma das formas com que os homens se engendram para produzir a própria existência, retomar a história da economia neoliberal, é entender primeiramente as premissas do liberalismo clássico, que tem como precursor Adam Smith (1723-1790) a partir da publicação de sua obra " $A$ riqueza das nações" (1776). Até esta publicação o eixo de explicação do homem era a filosofia. Em um período de transição do Medieval para o Moderno, o mercantilismo e as atividades feudais, o liberalismo clássico e suas ideias surgem contra o que já estava posto: o Estado Mercantilista, as instituições reguladoras do feudalismo, das corporações de ofício. As ideias de Adam Smith tiveram uma grande influência na burguesia europeia do século XVIII, pois atacavam e contestavam o regime de direitos feudais que ainda persistia em muitas regiões rurais da Europa.

Sabe-se que a partir do século $V$ se estendendo por todo período medieval, feudalista (séculos $\mathrm{V}$ a XV) a Igreja influenciou e dominou toda a sociedade europeia não se limitando apenas à religião, mas política, cultura, social e economicamente. Tem que falar a partir de que período ou mudar a frase $\mathrm{Na}$ área educacional, o ensino era voltado principalmente as doutrinas da religião católica. A Igreja era a detentora do saber, os livros pertenciam ao clero e ficavam confinados nas bibliotecas das igrejas, com uso exclusivo de seus membros. Já próximo a sua decadência, o sistema feudal passou por crises, a crise agrícola, a estagnação do comércio, fome, pestes, guerras e rebeliões. Conviveu com o Renascimento Comercial e Urbano, as reformas do cristianismo e o aparecimento de uma nova classe social: a burguesia.

A partir do século XIII, houve muitas e grandes transformações na Europa, que levou a derrocada do mundo medieval e ao surgimento da Modernidade. Na França já não era o governante 
"o príncipe" quem determinava a religião que o povo deveria seguir, pós reforma desenvolvida também por Calvino, seguido pelo movimento cultural da elite intelectual europeia - o lluminismo; em Portugal havia o crescimento do conhecimento náutico, escolas de navegação, construção de caravelas capazes de atravessar oceanos; a Espanha absorveria os conhecimentos náuticos de Portugal e se tornaria uma grande potência na área de instrumentação e produção deste conhecimento; na Alemanha surge um novo movimento liderado por Lutero somado posteriormente pela guerra dos camponeses; e por fim na Inglaterra, uma das filhas preferidas da Igreja de Roma até então, por meio do seu rei Henrique VIII decreta o Ato de Supremacia Real (1534) declarando ser o rei também líder da igreja, agora Anglicana, rompendo assim com Roma.

Em meio a esta efervescência europeia, somada a descoberta das Américas e assim a materialização das necessidades, a proposta de Adam Smith se fundamenta neste novo homem e novas relações sociais. Pois este novo homem, nascido no contexto de novas relações sociais só pode ser explicado dentro desta nova relação - a economia:

[...] uma vez eliminados inteiramente todos os sistemas, sejam eles preferenciais ou de restrições, impõe-se por si mesmo o sis- tema óbvio e simples da liberdade natural. Deixa-se a cada qual, enquanto não violar as leis da justiça, perfeita liberdade de ir em busca de seu próprio interesse, a seu próprio modo, e faça com que tanto seu trabalho como seu capital concorram com os de qualquer outra pessoa ou categoria de pessoas (SMITH, 1983, p.47).

Smith sintetiza, o que considerava as virtudes organizadoras e harmonizadoras, que via no mercado e que se expressaria em uma espécie de "mão invisível" que conduziria os atos.

[...] os interesses e os sentimentos privados dos indivíduos os induzem a converter seu capital para as aplicações que, em casos ordinários, são as mais vantajosas para a sociedade [...]. Sem qualquer intervenção da lei, os interesses e os sentimentos privados das pessoas naturalmente as levam a dividir e distribuir o capital de cada sociedade entre todas as diversas aplicações nela efetuadas, na medida do possível, na proporção mais condizente com o interesse de toda a sociedade (SMITH, 1983, p.104).

Ainda sobre isso Morais afirma que:

Smith afirma que o mundo seria melhor - mais justo, racional, eficiente e produtivo - se houvesse a mais livre iniciativa, se as atitudes econômicas dos indivíduos e suas relações não fossem limitadas por regulamentos e monopólios garantidos pelo Estado ou pelas corporações de ofício. Prega a necessidade de desregulamentar e privatizar as atividades econômicas, reduzindo o Estado a funções definidas, que delimitassem apenas parâmetros bastante gerais para as atividades livres dos agentes econômicos. (MORAIS, 2001, p.5)

Smith, filósofo e economista escocês do século XVIII, nasceu na cidade de Kirkcaldy, em 5 de junho de 1723, e faleceu em Edimburgo no dia 17 de julho de 1790. Sua principal teoria baseava-se na ideia de que deveria haver total liberdade econômica para que a iniciativa privada pudesse se desenvolver, sem a intervenção do Estado. A livre concorrência entre os empresários regularia o mercado, provocando a queda de preços, e o aumento das inovações tecnológicas necessárias para melhorar a qualidade dos produtos e aumentar o ritmo de produção.

A argumentação de Smith é clara. Para que o mundo seja mais livre, justo e rico, é necessário que a disciplina anônima e invisível da concorrência subs- 
titua a disciplina visível das hierarquias arcaicas. E onde estão essas hierarquias perniciosas? São as obrigações tradicionais e personalizadas das instituições medievais, os regulamentos das corporações de ofício e as leis do Estado mercantilista. Smith elogia a virtuosa mão invisível do mercado contra a viciosa mão visível do poder político. (MORAIS, 2001, p.7)

Assim, Smith e os demais autores do liberalismo clássico afirmam que o "sistema de liberdade natural", é tão evidentemente vantajoso para todos que tudo que for contrário a esta ideia deve ser eliminado. A ideia principal é a de que o desenvolvimento e o bem estar de uma nação advém do crescimento econômico e da divisão do trabalho. Esta última, garante a redução dos custos de produção e a queda dos preços das mercadorias. E a livre concorrência econômica e a acumulação de capital deve ser a fonte para o desenvolvimento econômico.

Desenhado então as premissas do início do sistema capitalista com o liberalismo clássico, pode-se questionar quais influências esse contexto teve na educação, para educar este novo homem nestas novas relações sociais, burguesas, necessário foi adotar uma ideologia que sustentasse o capitalismo, abraçaram então a ideia do Positivismo de August Comte (1798-1857), criando assim o pensamento ordeiro, contrarrevolucionário garantindo a reprodução dessa nova forma de pensar.

A afirmação de Adam Smith na metade do século XVIII - de todos os homens são iguais, e esta igualdade vem da capacidade de produzir trabalho, onde a riqueza que conta é a produção social - foi o início da economia clássica. As principais discussões econômicas capitalistas perpassam por David Ricardo (1772-1823) que faz a distinção entre riqueza e valor, dando fim a economia burguesa, com a decadência da manufatura e início da maquinaria, desenhou os conceitos sobre capital, renda, salário, produção, preços e mercados, muitos deles encontrados até hoje. Com Karl Marx (1818-1883) que estudou a fundo este sistema e seus ditames, deslindou, registrou e denunciou os economistas e os meandros do capital. Em toda sua trajetória, a compreensão da realidade concreta encontra-se registrada em suas obras, onde afirma que a História da humanidade é a História da luta de classes. Também com o economista britânico John Keynes (18831946) que em seu conjunto de ideias propunha a intervenção estatal na vida econômica com o objetivo de conduzir a um regime de pleno emprego sem o aumento da inflação e para isso via a economia como instrumento de política e portanto deveria ser afastada das ciências naturais, onde suas decisões fossem individuais e centralizadas. Keynes ao relatar que a economia do capitalismo preocupava-se com os homens e não indivíduos, objetivando a acumulação de riqueza monetária para comprar produção e força de trabalho e assim ter mais riqueza monetária, revelou que seu desejo era a eutanásia do rentismo, pregou a socialização dos investimentos, afirmou que o sistema capitalista ao mesmo tempo que aumenta suas virtudes, amplia seus desafios, para ele o capitalismo "bem domesticado" poderia se comportar bem. Utópico ou não, fato é que uma das suas principais contribuição para a economia foi o fim do "laissez-faire" - deixar fazer, deixar acontecer ao criar a Teoria Geral do emprego, do juro e do dinheiro.

Todas aquelas discussões e críticas, bem como as ideias apresentadas por Keynes em sua Teoria Geral também foram sendo modeladas pelos acontecimentos históricos; particularmente pela Grande Depressão, a crise de 1929. Este novo cenário de instabilidade econômica, culminou na 2a guerra mundial, e é neste contexto que surge a nova ideologia no início século XX - o Neoliberalismo com Ludwig von Mises (1881-1973) e Friedrich von Hayek (1899 - 1992):

[...] o neoliberalismo, [...], é a ideologia do capitalismo na era de máxima financeirização da riqueza, a era da riqueza mais líquida, a era do capital volátil - e um ataque às formas de regulação econômica do século XX, como o socialismo, o keynesianismo, o Estado de bem-estar, o terceiro mundismo e o desenvolvimento latino-americano. (MORAES, 2001, p.4) 
Esta nova ideologia doutrinária proposta por estes e outros economistas franceses, alemães e norte-americanos, na primeira metade do século XX, se volta para a adaptação dos princípios do liberalismo clássico às exigências de um Estado regulador e assistencialista, que deveria controlar parcialmente o funcionamento do mercado:

O liberalismo clássico havia assestado suas baterias contra o Estado mercantilista e as corporações. Os neoliberais procuraram desde logo construir um paralelo com aquela situação, para justificar seu combate e apresentálo como a continuação de uma respeitável campanha antiabsolutista. Segundo eles, os inimigos vestiam agora outros trajes, mas revelavam as mesmas taras e perversões. Um desses inimigos era o conjunto institucional composto pelo Estado de bem-estar social, pela planificação e pela intervenção estatal na economia, tudo isso identificado com a doutrina keynesiana. (MORAIS, 2001, p.13)

Princípios estes que ganharam forças após a grande crise do capital de 1973, com o crescimento da concorrência comercial e com a necessidade de sustentar a suposta supremacia que o capitalismo demonstrava conquistar sobre o sistema socialista. No Brasil, em decorrência do Regime Militar, esse processo se inicia um pouco mais tarde. Sobre esse processo Pablo Gentili afirma ser um ambicioso projeto de reforma ideológica:

Com efeito, o neoliberalismo expressa a dupla dinâmica que caracteriza todo processo de construção de hegemonia. Por um lado, trata-se de uma alternativa de poder extremamente vigorosa constituída por uma série de estratégias políticas, econômicas e jurídicas orientadas para encontrar uma saída dominante para a crise capitalista que se inicia ao final dos anos $60 \mathrm{e}$ que se manifesta claramente já nos anos 70. Por outro lado, ela expressa e sintetiza um ambicioso projeto de reforma ideológica de nossas sociedades a construção e a difusão de um novo senso comum que fornece coerência, sentido e uma pretensa legitimidade às propostas de reforma impulsionadas pelo bloco dominante. (GENTILI, 1999, p.9)

Em todas as escolas do pensamento neoliberal, os "ajustes estruturais" por meio de suas políticas públicas são a de focalizar - substituindo a política de acesso universal pelo acesso seletivo; descentralizar - operações, sobretudo as decisões políticas mais estratégicas de gestão de grandes fundos, e privatizar:

Enfim, mas não menos importante, privatizar Isto pode ser feito, basicamente, por duas vias. A primeira é transferir ao setor privado a propriedade dos entes estatais (inclusive os entes provedores de políticas sociais, tais como saúde, educação, moradia, assistência social, etc.). A segunda via é transferir ao setor privado a operação e/ou gestão dos serviços (o que traz à baila a velha diferenciação, da teoria das finanças públicas, sobre provisão e produção dos serviços públicos). (MORAES, 2001, p.37,38 grifo nosso)

Assim, o Neoliberalismo predispõe ações de redução gradativa na intervenção do Estado na economia e na sociedade e reduz o indivíduo a mero consumidor priorizando não mais a liberdade do indivíduo e sim a liberdade econômica das grandes organizações, cabe discutir qual a sua influência na qualidade educacional. O neoliberalismo propõe o modelo educacional baseado no trabalho alienado que está ligado à divisão entre os super - produto da classe dominante - detentores da cultura, bastidores dos fatos ou ainda autores; e a base - classe dominada - atores das decisões da classe dominante, ou seja, a educação pretendida insere-se no modelo de homem 
pretendido pelo capitalismo. Como prevê, o art 10 § 2 을 da LD $n$ ㅇ 9394/96 que direciona a educação escolar primeiramente para o mundo do trabalho, enfatizando uma educação unilateral, mais técnica e reprodutiva.

Esse tipo de formação perpetua a desigualdade e a exclusão. A permanência da desigualdade, os discriminados de ontem continuam a ser os discriminados de hoje, perpassando pelo comprometimento da educação com o período histórico que pretende atender. Na visão de Marx, a história se faz pela luta de interesses registrada pela luta de classes. Assim, os discriminados são os mesmos, mas as desigualdades se fundamentam de formas diferentes, justamente porque o contexto histórico é diferente e exige demandas diferentes. A desigualdade é fruto de um processo histórico que a alimenta e reproduz, pois a sua essência está numa formação para o trabalho em um sistema capitalista.

Ao educar-se para o trabalho, há que se pensar que a desigualdade educativa parece proposital e a má qualidade do ensino pode justificar que o acesso à escola se dá pela necessidade de preparar mão de obra para o trabalho e o trabalho aqui existe com a finalidade de atender aos interesses da classe dominadora, ou seja, o objetivo seria formar o homem unilateral.

A cisão entre os que produzem, mas não usufruem dos resultados destes bens, quer sejam materiais ou imateriais é alimentada pelo capitalismo. Com o parcelamento da produção no taylorismo, o saber assumiu uma tendência de desapropriação. Ao estudar tempo e movimento, Taylor propôs a produção do trabalho de forma fragmentada e essa influência se perpetuou na escola com uma divisão do conhecimento teórico e prático. Para uma efetiva transformação nos padrões de coletividade faz-se necessário uma nova forma de se compreender a educação e o trabalho educativo.

\section{DISCUSSÃO}

Ao estudar a gênese do capitalismo, e traçar paralelos entre a economia e a organização da vida social, Marx estabeleceu algumas categorias que servem de instrumentos para melhor compreender o momento presente e, permitir ao homem identificar-se como autor e ator histórico. Ao estabelecer o trabalho, como categoria básica em sua análise desmascarou as contradições e a alienação inerente ao sistema que acentua as desigualdades sociais. Sobre a alienação Marx questiona:

Mas como posso ser virtuoso, se não sou? Como posso ter boa consciência, se não sei nada? Tudo isto está fundado na essência da alienação: cada uma aplica-me uma medida diferente e oposta, a moral aplica-me uma e a economia política outra, porque cada uma destas é uma determinada alienação do homem e [...] fixa um círculo particular da atividade essencial alienada; cada uma delas se relaciona de forma alienada com a outra alienação [...]. (MARX, 1978, p.19)

Marx descortinou o processo dinâmico, vivo e sempre sujeito a alterações que pelo trabaIho impulsiona transformações históricas nas quais o homem transforma ao mesmo tempo em que é transformado.

Ao transformar a forma de produzir a vida pelo trabalho, o homem gesta conceitos, normas e teorias que fundamentem seus atos, o que segundo Saviani, em "Escola e Democracia: polêmicas do nosso tempo" (1999) redundam em patrimônio cultural adquirido que lhe permite exercer domínio sobre outras classes. Desvendar então, o mundo do trabalho é descortinar a própria vida, e compreender como se organizam os homens, permite compreender suas práticas que sempre se fundamentam em uma teoria de suporte.

Sobre a questão educacional, Marx expõe: 
A doutrina materialista da transformação das circunstâncias e da educação esquece que as circunstâncias têm de ser transformadas pelos homens e que o próprio educador tem que ser educado. Daí que ela tenha de cindir a sociedade em duas partes - uma das quais fica elevada acima dela. A coincidência da mudança das circunstâncias e da atividade humana ou da autotransformação só pode ser tomada e racionalmente entendida como práxis revolucionária. (MARX, 1984, p. 108).

Um dos primeiros obstáculos que a educação tem que superar é a separação entre concreto e abstrato. O pensamento parte do empírico, mas, tem como suporte o real concreto, pode-se dizer que o concreto-ponto de partida é o concreto real e o concreto-ponto de chegada é o concreto pensado, isto é, a teoria é a apropriação pelo pensamento do real-concreto, e quem a domina impõe pela ideologia a sua visão de mundo. Assim, o verdadeiro ponto de partida, bem como ponto de chegada é o concreto real. E, o concreto é histórico, ele se dá e se revela pela práxis.

A produção do saber é social, logo, ocorre no interior das relações sociais. A elaboração do saber implica expressar de forma sistematizada o saber que surge da prática social. Essa expressão elaborada supõe o domínio dos instrumentos de elaboração e sistematização. Pela divisão do trabalho, e com ele do conhecimento, o trabalhador foi expropriado do conjunto da totalidade, ficando-Ihe restrito a percepção do conhecimento enquanto produção coletiva. Restando ao trabaIhador apenas parcelas, o conjunto passou a pertencer ao setor dominante que se apropriou da sua elaboração enquanto teoria, devolvendo ao trabalhador apenas a parcela relativa à operação que ele vai desenvolver no processo produtivo.

A grande contribuição de Marx e Engels neste sentido foi a preocupação de indicar o caminho para essa elaboração, o Método Materialismo Histórico, ao levantar na obra "A ideologia Alemã" algumas questões referentes à materialidade das questões teóricas e suas implicações na formação e na compreensão dos processos históricos que as constroem, os autores traçaram um viés que permite a compreensão e crítica da ideologia burguesa e suas implicações no processo educacional.

$\mathrm{Na}$ obra, Marx preocupou-se em desmistificar o processo educacional, partindo das relações sociais, tendo o trabalho como elemento de mediação, desvelando as contradições inerentes ao processo de construção da vida pela ótica do capital e de sua influência na produção da mesma. Estabeleceu um novo conceito de homem, partindo da análise da práxis para tecer então uma práxis revolucionária, que segundo ele, deveria começar pela formação do educador.

E, segundo Arnaldo Niskier (2001), no texto "Marxismo e Educação", toda fórmula educacional corresponde a uma ideologia e esta sempre estabelece relações de poder, acreditar que não existirá um dia relações de poder seria substituir uma ideologia por outra, mas, o que importa é incentivar a escola a assumir papel não de espectadora acrítica, mas, de incentivá-la a descortinar a seus educandos a possibilidade de conhecer, compreender e assumir suas próprias conclusões a respeito da produção da vida como atores e autores do seu momento histórico. É, nesse aspecto que a teoria e a prática se fundem e se completam, na compreensão do processo histórico, reconhecendo-se como sujeitos dele.

Lukács (1969) afirma ainda que a educação é um complexo dentro de uma sociedade complexa e se a sociedade só pode ser entendida numa perspectiva historicista, a educação também. Conforme afirmação em a Ideologia Alemã, a história é um instrumento que permite desvendar as contradições inerentes ao processo de construção da vida. O desenvolvimento humano é contraditório e heterogêneo, realizado por meio das concretas relações sociais de dominação que caracteriza a história humana até aqui.

Segundo Saviani (1991), Educação é um tema complexo, contudo a complexidade não deve ser considerada como um obstáculo intransponível, mas como um desafio a ser enfrentado. Discu- 
tir qualidade do ensino nos mostra a necessidade de amparados pela história e pela filosofia, fomentar a reflexão e o debate, instrumentalizados pelos clássicos, que buscam superar o imediato e o conjuntural, direcionando o processo educativo para os aspectos essenciais e duradouros. Sobre isso Marx afirma:

Se o homem forma todos seus conhecimentos, suas sensações etc. do mundo sensível e da experiência dentro desse mundo, o que importa, portanto, é organizar o mundo do espírito de tal modo que o homem faça aí a experiência, e assimile ao o hábito daquilo que é humano de verdade, que se experimente a si mesmo enquanto homem. [...] Se o homem é formado pelas circunstâncias, será necessário formar as circunstâncias humanamente. (MARX e ENGELS, 2003, p.149)

Assim, vê-se a importância da história e da filosofia da educação na formação do educador para discutir as questões sobre qualidade do ensino, desigualdade e exclusão.

\section{CONCLUSÃO}

Uma educação de qualidade, que visa diminuir as desigualdades, e oportunizar o conhecimento historicamente construído, deve perpassar pela formação da consciência crítica, portanto, abarca a capacidade de pensar a ação em suas continuidades e mudanças do tempo, em uma reflexão mais ampla e crítica do conhecimento da economia política, que possibilita descortinar a construção do pensamento capitalista. Neste contexto é que se apresenta a necessidade de formar um homem omnilateral, que não domine somente o conhecimento técnico, mas também seja habilitado em uma formação filosófica e política, no sentido de capacitá-lo a tornar-se não somente ator, mas também autor; capaz de fazer uma leitura e interpretação do contexto histórico em que se insere e não somente reproduzi-lo. Capaz de analisar criticamente a realidade e transformá-la como sujeito histórico que, pelo trabalho (manual e intelectual), produz suas condições objetivas de vida individual e em sociedade.

Diante dessas constatações, e da perspectiva de que o processo educacional, apesar de suas limitações, pode contribuir para uma melhoria social, faz-se necessário pensar a educação de forma integral, fomentar a formação de homens livres e conscientes que sejam capazes de desvelar a forma de produção material camuflada no neoliberalismo; refletindo e transformando-se no conjunto das relações sociais.

\section{REFERÊNCIAS}

BRASIL, L. D. B. Lei 9394/96 - Lei de Diretrizes e Bases da Educação Nacional. Disponível http://www. planalto. gov. br/ccivil_03/leis/19394. htm. Acesso em 23/08/2016, v. 30, 2013.

GENTILI, Pablo; SILVA, Tomaz Tadeu. Escola S. A. Quem Ganha e Quem Perde no Mercado Educacional do Neoliberalismo. Brasília: CNTE, 1999.

GENTILI, Pablo. Neoliberalismo e educação: manual do usuário. In: GENTILI, Pablo; SILVA, Tomaz Tadeu (Orgs.). Escola S.A.: quem ganha e quem perde no mercado educacional do neoliberalismo. Brasília: CNTE, 1999. p. 9-49.

LUKÁCS, Georg. Conversando com Lukács. Rio de Janeiro: Paz e Terra, 1969. 
MARX, Karl. Manuscritos Econômico-Filosóficos - Terceiro Manuscrito. In: Marx, K. Manuscritos econômico-filosóficos e outros textos escolhidos. São Paulo: Abril Cultural - Coleção Os Pensadores, 1978, p. 3-48.

MARX, Karl; ENGELS, Friedrich. A Ideologia Alemã. São Paulo: Ed. Moraes Ltda., 1984.

A Sagrada Família. São Paulo: Boitempo, 2003.

MORAIS, Reginaldo C. Neoliberalismo - de onde vem, para onde vai? Senac, São Paulo: 2001.

NISKIER, Arnaldo. Filosofia da educação: uma visão crítica. Edições Loyola, 2001.

SAVIANI, Dermeval. Educação: do senso comum à consciência filosófica. São Paulo: Cortez: Autores Associados, 1991.

Escola e Democracia: polêmicas do nosso tempo. São Paulo: Autores Associados,

1999.

SMITH, Adam - A Riqueza das Nações - investigação sobre sua natureza e suas causas, São Paulo, Abril Cultural, 1983, v. II. 